\title{
Stabilization of N-, N,N-, N,N'-methylated and unsubstituted simple amidine salts by multifurcated hydrogen bonds
}

\author{
Jarosław Spychała \\ Department of Chemistry, Adam Mickiewicz University, Grunwaldzka 6, 60-780 Poznań, Poland
}

\begin{abstract}
In the light of the usefulness of amidines in medicinal chemistry, this paper considers the effects on biological properties and chemical reactivities of organic molecules affected by intramolecular interactions. The study of chemical shifts has been an important source of information on the electronic structure of amidine salts and their ability to form non-covalent bonds with nucleic acids. The NMR and IR results demonstrate that hydrogen bonds are a force for promoting chemical reactions. The thymine $\mathrm{O} 2$ carbonyl oxygen in a close proximity to the amidinium cation does interact with the appropriately spaced amidinium NH donor moieties. The ${ }^{1} \mathrm{H}^{15} \mathrm{~N} 2 \mathrm{D}$ NMR (GHSQC and GHMBC) spectra with natural isotopic abundance of ${ }^{15} \mathrm{~N}$ fully confirm the intramolecular character of the bonds. A rule able to estimate the relative strength of the new multifurcated hydrogen bonds is given. The appearance of the $\Delta \delta_{\mathrm{N} H}$ chemical shift differences near zero is due to the strong intramolecular interactions. The strength of the $\mathrm{H}$-bond donation by acetamidines is reflected in the $\mathrm{N}-\mathrm{H}$ dissociation/recombination process (positive charge shift has been invoked to explain other effects on benzamidines). The temperature dependence of chemical shift for the amidine $\mathrm{NH}$ protons in dimethyl sulfoxide solutions is herein discussed.
\end{abstract}

Keywords: Ionic hydrogen bonding, ${ }^{1} \mathrm{H}_{-}{ }^{15} \mathrm{~N}$ spin-spin interactions, acetamidines, benzamidines

\section{Introduction}

The amidines are present in many natural and synthetic products with a range of pharmacological activities [1-7], including antithrombotic, antihypercholesterolemic, antihyperglycemic, antihypertensive, anti-inflammatory, antihistaminic, ambecidal, and anticancer activities. Factors such as the nature of substrates and stabilizing effects on biologically important macromolecules, may influence the aggregation and recognition in nature, and can greatly increase the synthetic significance of the reactions. The comparison of structural properties of the products, based on NMR measurements, may help us to understand more about the role of hydrogen bonds in the mechanistic pathways.

Hydrogen-bonding interaction (classical or charged) has been extensively studied in solution and the solid state [8-14]. The relative donor and acceptor capabilities (angles, arrangement, distances, spectroscopic features, structure, type) and the additional effects (cooperative, anticooperative, competitive, synergetic) influence the strength of hydrogen bonds $[15,16]$. The dependence of reactivity and stabilization of the products in the hydrolysis and cyclization reactions on the hydrogen bonding systems appears to be very important (strong hydrogen bonds in substrates or intermediates inhibit the reaction and the weaker types facilitate it) [17].

Stabilization of the products of the reaction of thioamides with zinc ammoniates [18] has prompted this investigation, which provides additional inside concerning the new multifurcated ionic hydrogen bonds. The study of model structures may be useful for detection of interactions of amidines with nucleic acids. 


\section{Experimental}

\subsection{Materials}

Melting points are uncorrected and were determined by using a Boetius melting-point apparatus. Thinlayer chromatography was performed with Merck silica gel $60 \mathrm{~F}_{254}$ glass plates $(0.25 \mathrm{~mm}$ thickness $)$ in the appropriate solvent systems: $44: 8: 1,11: 4: 1,7: 5: 2 \mathrm{CHCl}_{3}-\mathrm{CH}_{3} \mathrm{OH}-\mathrm{NH}_{4} \mathrm{OH}$. It was applied for purity determination. Full details of the characterization data of 1-7 [18], 11 [19], and 12 [20] have been reported elsewhere. Final samples were dried first in an oven at $110^{\circ} \mathrm{C}$ and then stored in a vacuum desiccator over $\mathrm{P}_{2} \mathrm{O}_{5}$.

\subsection{Measurements}

${ }^{1} \mathrm{H}$ and ${ }^{13} \mathrm{C}$ NMR spectra were recorded on a Varian 300 Gemini spectrometer in (methyl sulfoxide)- $d_{6}$ with TMS as an internal standard and IR spectra on a Bruker 113v FT-IR spectrometer ( $\nu_{\max }, \mathrm{KBr}$ discs). The standard GHSQC and GHMBC spectra were measured with magnetic field gradients on a Bruker spectrometer operating at the following resonance frequencies: $600.2 \mathrm{MHz}$ for ${ }^{1} \mathrm{H}$ and $60.8 \mathrm{MHz}$ for ${ }^{15} \mathrm{~N}$ (accuracy of data, $0.05 \mathrm{ppm}$ ). Sweep width and data points in both dimensions (GHSQC: 1, $7441 \mathrm{~Hz}$, $1024 \times 256 ; \mathbf{1 1}, 7441 \mathrm{~Hz}, 1024 \times 256$. GHMBC: $1,7441 \mathrm{~Hz}, 1024 \times 256 ; \mathbf{1 1}, 7441 \mathrm{~Hz}, 1024 \times 110)$. The pulse parameters are as follows: acquisition time, $0.067-0.072 \mathrm{~s} ; \pi / 2$ pulse lengths, $19.0 \mu \mathrm{s}$; relaxation delay, $1 \mathrm{~s}$. The ${ }^{15} \mathrm{~N}$ resonances were referenced to the signal of liquid $\mathrm{CH}_{3} \mathrm{NO}_{2}(\delta=381.7 \mathrm{ppm})$. Hence are the positive chemical shifts to lower frequency from this external reference. All spectra were obtained with the natural abundance of the nitrogen-15 isotope over the temperature range 295.7-303.1 K.

\subsection{Temperature reversibility studies}

In order to clarify the intramolecular character of the hydrogen bonds, several temperatures were tested for their effect on the chemical shifts. Both $\mathbf{1}$ and 3a display so-called 'red shift' upon heating, as judged from their proton spectra. In a similar fashion, effects associated with the change of temperatures were observed for 2.

1: $\delta_{\mathrm{H}}\left(50^{\circ} \mathrm{C}\right) 1.77\left(\mathrm{~d}, 3 \mathrm{H}, J=1.1 \mathrm{~Hz}, \mathrm{C} 5 \mathrm{CH}_{3}\right), 4.66\left(\mathrm{~s}, 2 \mathrm{H}, \mathrm{N} 1 \mathrm{C} H_{2}\right), 7.51(\mathrm{~d}, 1 \mathrm{H}, J=1.1 \mathrm{~Hz}, \mathrm{C} 6 \mathrm{H})$, $9.11(\mathrm{~s}, 4 \mathrm{H}$, 'inside' and 'outside' $\mathrm{N} H), 11.30(\mathrm{~s}, 1 \mathrm{H}, \mathrm{N} 3 H) ; \delta_{\mathrm{H}}\left(70^{\circ} \mathrm{C}\right) 1.77(\mathrm{~d}, 3 \mathrm{H}, J=1.1 \mathrm{~Hz}), 4.66$ $(\mathrm{s}, 2 \mathrm{H}), 7.50(\mathrm{~d}, 1 \mathrm{H}, J=1.4 \mathrm{~Hz}), 9.08(\mathrm{~s}, 2 \mathrm{H}, \mathrm{N} H), 9.12\left(\mathrm{~s}, 2 \mathrm{H}, \mathrm{N} H, \Delta \delta_{\mathrm{N} H} 0.04 \mathrm{ppm}\right), 11.22(\mathrm{~s}, 1 \mathrm{H})$; $\delta_{\mathrm{H}}\left(90^{\circ} \mathrm{C}\right) 1.80(\mathrm{~d}, 3 \mathrm{H}, J=1.1 \mathrm{~Hz}), 4.69(\mathrm{~s}, 2 \mathrm{H}), 7.51(\mathrm{~d}, 1 \mathrm{H}, J=1.4 \mathrm{~Hz}), 9.09(\mathrm{br} \mathrm{s}, 4 \mathrm{H}, \mathrm{NH}), 11.14$ (br s, 1H).

The bands of 1 at $\nu_{\max } 2799 \mathrm{~cm}^{-1}$ and $2760 \mathrm{~cm}^{-1}$ are also bathochromically shifted with respect to salts $11\left(2819 \mathrm{~cm}^{-1}\right)$ and $\mathbf{1 2}\left(2804 \mathrm{~cm}^{-1}, 2777 \mathrm{~cm}^{-1}\right)$.

2: $\delta_{\mathrm{H}}\left(50^{\circ} \mathrm{C}\right) 1.77\left(\mathrm{~d}, 3 \mathrm{H}, J=0.8 \mathrm{~Hz}, \mathrm{CH}_{3}\right), 4.92(\mathrm{~s}, 2 \mathrm{H}, \mathrm{CH}), 7.50-7.80\left(\mathrm{~m}, 4 \mathrm{H}, \mathrm{C}_{6} H_{4}\right), 9.09$ (br $\left.\mathrm{s}, 4 \mathrm{H}, \mathrm{H}_{2} \mathrm{NC}^{+} \mathrm{N} H_{2}\right)$, the $\mathrm{N} 3 \mathrm{H}$ signal is very broadened; $\delta_{\mathrm{H}}\left(70^{\circ} \mathrm{C}\right) 1.78(\mathrm{~d}, 3 \mathrm{H}, J=1.1 \mathrm{~Hz}), 4.93(\mathrm{~s}$, $2 \mathrm{H}), 7.50-7.80(\mathrm{~m}, 4 \mathrm{H}), 9.25\left(\mathrm{br} \mathrm{s}, 5 \mathrm{H}, \mathrm{N} 3 \mathrm{H}^{\cdots} \mathrm{H}_{2} \mathrm{NC}^{+} \mathrm{N} H_{2}\right.$, cooperative hydrogen bonding); $\delta_{\mathrm{H}}\left(90^{\circ} \mathrm{C}\right)$ $1.78(\mathrm{~d}, 3 \mathrm{H}, J=1.1 \mathrm{~Hz}), 4.92$ (s, 2H), 7.50-7.80 (m, 4H), 9.21 (br s, 5H).

3a: $\delta_{\mathrm{H}}\left(50^{\circ} \mathrm{C}\right) 1.78\left(\mathrm{~d}, 3 \mathrm{H}, J=1.4 \mathrm{~Hz}, \mathrm{C} 5 \mathrm{CH}_{3}\right), 2.83$ (s, 3H, 'inside' $\left.\mathrm{NCH}_{3}\right), 3.00$ (s, 3H, 'outside' $\left.\mathrm{NCH}_{3}\right), 4.85\left(\mathrm{~s}, 2 \mathrm{H}, \mathrm{N} 1 \mathrm{CH}_{2}\right), 7.45(\mathrm{~d}, 1 \mathrm{H}, J=1.4 \mathrm{~Hz}, \mathrm{C} 6 H), 9.07$ (br s, 2H, NH), 11.37 (br s, $1 \mathrm{H}$, $\mathrm{N} 3 H) ; \delta_{\mathrm{H}}\left(70^{\circ} \mathrm{C}\right) 1.78(\mathrm{~d}, 3 \mathrm{H}, J=1.1 \mathrm{~Hz}), 2.84(\mathrm{~s}, 3 \mathrm{H}), 3.01(\mathrm{~s}, 3 \mathrm{H}), 4.84(\mathrm{~s}, 2 \mathrm{H}), 7.44(\mathrm{~d}, 1 \mathrm{H}$, $J=1.1 \mathrm{~Hz}), 9.05(\mathrm{br} \mathrm{s}, 2 \mathrm{H}), 11.28(\mathrm{br} \mathrm{s}, 1 \mathrm{H}) ; \delta_{\mathrm{H}}\left(90^{\circ} \mathrm{C}\right) 1.79(\mathrm{~d}, 3 \mathrm{H}, J=1.1 \mathrm{~Hz}), 2.86(\mathrm{~s}, 3 \mathrm{H}), 3.03$ (s, 3H), 4.83 (s, 2H), 7.43 (d, 1H, $J=1.1 \mathrm{~Hz}), 9.04$ (br s, 2H), 11.18 (br s, 1H). 
Routine NMR data (for comparison with 2) reported below for benzamidine hydrochloride (Aldrich) were obtained at standard conditions. $\delta_{\mathrm{H}} 7.62(\mathrm{tt}, 2 \mathrm{H}, J=7.6,1.5 \mathrm{~Hz}), 7.75(\mathrm{tt}, 1 \mathrm{H}, J=7.4,1.5 \mathrm{~Hz})$, $7.88(\mathrm{dt}, 2 \mathrm{H}, J=7.1,1.6 \mathrm{~Hz}), 9.44\left(\mathrm{~s}, 4 \mathrm{H}, H_{2} \mathrm{NC}^{+} \mathrm{N} H_{2}\right) ; \delta_{\mathrm{C}} 127.8,127.9,128.8,133.6,165.6$ $\left(\mathrm{H}_{2} \mathrm{NC}^{+} \mathrm{NH}_{2}\right)$.

\section{Results and discussion}

Unsubstituted (1-2), $N$-methyl- (5-7), $N, N$-dimethyl- (4), and $N, N^{\prime}$-dimethyl (3) amidinium chlorides are products of the reaction of appropriate thioamides with zinc ammoniates [18]. The product yield depends on the thioamide or alkylamine used. Thus, it is of fundamental importance to prove and explain the molecular structures.

\section{1. ${ }^{1} \mathrm{H}$ and ${ }^{13} \mathrm{C} N M R$ evidence for the intramolecular hydrogen bonds of unsubstituted amidines $\mathbf{1}$ and 2}

On the basis of accessible spectra, it is possible to decide exactly the structure in solution of all amidines investigated. The analysis of chemical shifts can determine intramolecular hydrogen bond character. The NMR and IR data of 1-( $\omega$-amidinoalkyl)thymine hydrochlorides 1-4 and 11-12 reveal features typical for intramolecular hydrogen bonding schemes. The conformational preferences for these structures may be reasonably pictured, as shown in Scheme 1. Several relations between the structure and chemical shifts of the simple amidines can be formulated.

Two nitrogen atoms of (1-thyminyl)acetamidine hydrochloride (1) approach symmetrically the carbonyl oxygen in the middle from the appropriate side, as indicated by dashed lines. The ${ }^{1} \mathrm{H}$ NMR spectrum (Fig. 1) exhibits two $\mathrm{N} H$ sharp singlets of equal area, not far off $\left(\Delta \delta_{\mathrm{N} H} 0.02 \mathrm{ppm}\right)$, but on heating to $50^{\circ} \mathrm{C}$ the nearby sharp singlets are transformed into one sharp singlet (A). Further broadening due to

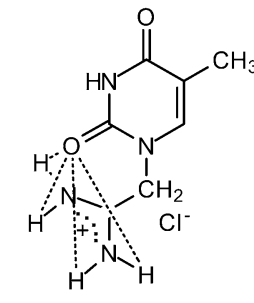

1

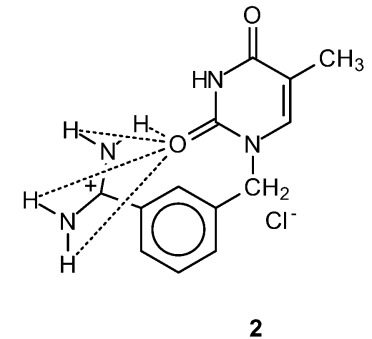

2

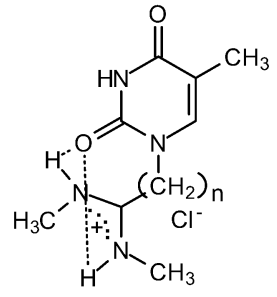

3<smiles>CN=C(Cl)Cn1cc(C)c(=O)[nH]c1=O</smiles>

4<smiles></smiles>

5

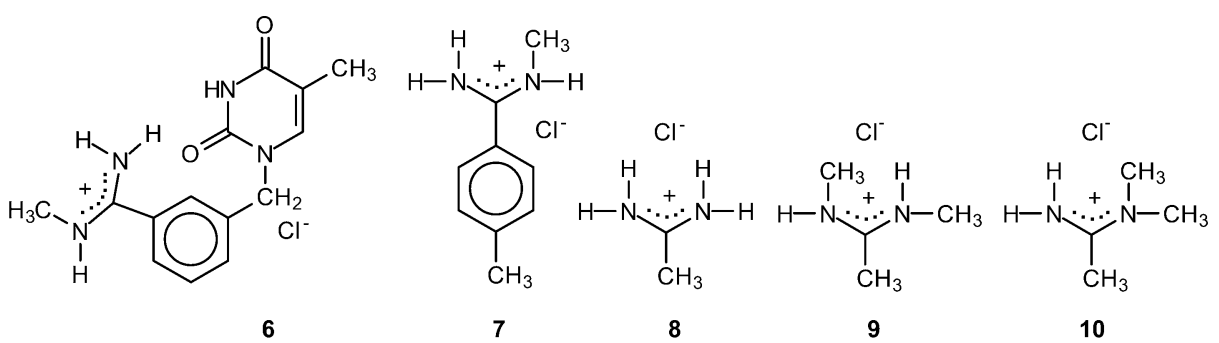

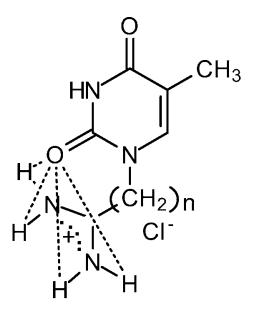

$11(n=3)$ and $12(n=4)$

Scheme 1. Unsubstituted $(\mathbf{1}, \mathbf{2}, \mathbf{8}, \mathbf{1 1}, \mathbf{1 2}), N$-methyl- $(\mathbf{5}, \mathbf{6}, \mathbf{7}), N, N$-dimethyl- $(\mathbf{4}, \mathbf{1 0})$, and $N, N^{\prime}$-dimethyl $(\mathbf{3}, \mathbf{9})$ amidinium chlorides investigated in this work. 
A

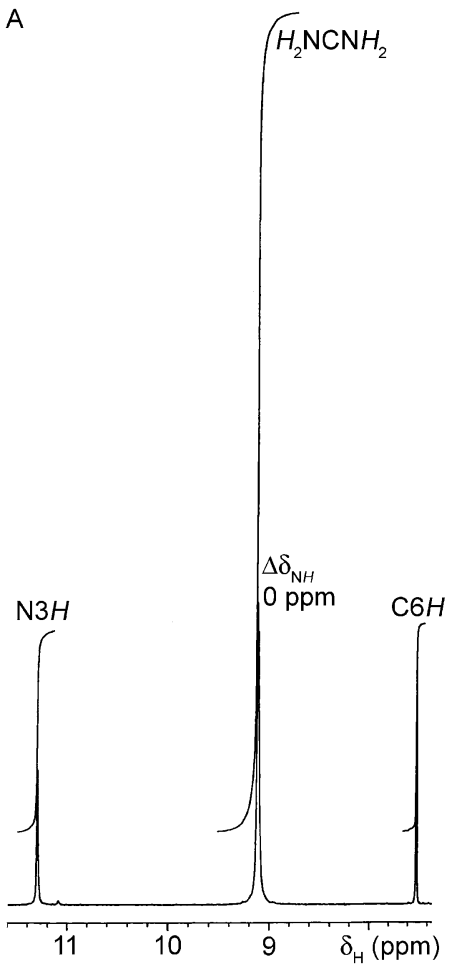

B

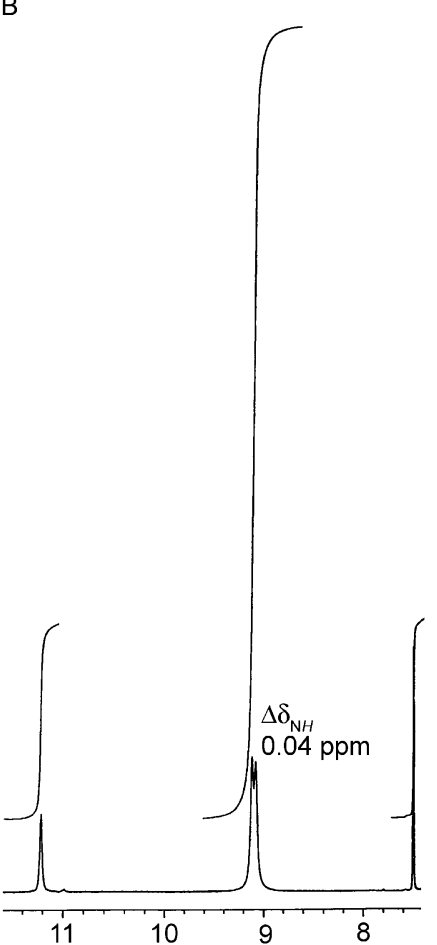

C

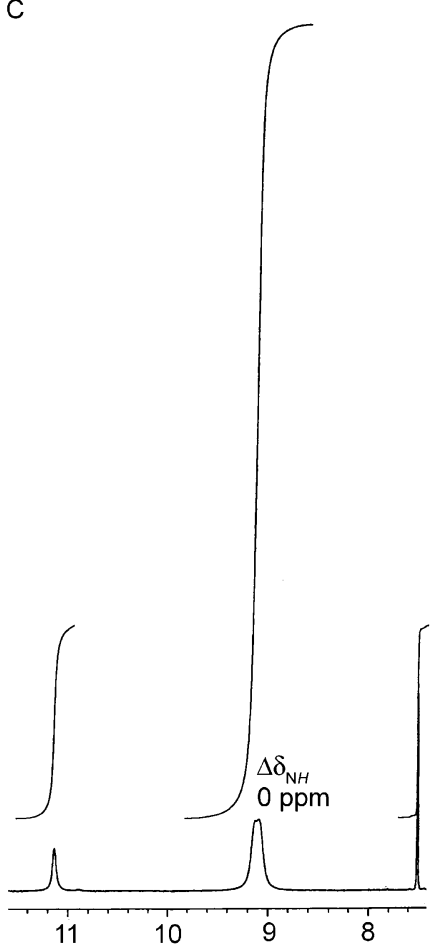

Fig. 1. Effect of temperature on the ${ }^{1} \mathrm{H}$ NMR spectrum of 1, measured at a single concentration of $10 \mathrm{mg}$ in $0.5 \mathrm{ml}$ of dimethyl sulfoxide: (A) $50^{\circ} \mathrm{C}$, (B) $70^{\circ} \mathrm{C}$, (C) $90^{\circ} \mathrm{C}$.

rapid proton exchange and splitting of the signal into two singlets $\left(\mathrm{B}, \Delta \delta_{\mathrm{N} H} 0.04 \mathrm{ppm}\right)$ are observed for 1 at $70^{\circ} \mathrm{C}$ and one-broad singlet pattern (C) arises again at $90^{\circ} \mathrm{C}$ (an upfield shift, so-called 'red shifting' appears as temperature increases). In addition, structure $\mathbf{1}$ is characterized by considerable shielding by $3.4 \mathrm{ppm}$ of the amidinium $\mathrm{H}_{2} \mathrm{NCNH}_{2}$ carbon nucleus with respect to the appropriate value of $\mathbf{1 1}$ and $4.3 \mathrm{ppm}$ for $\mathbf{1 2}$.

The origin of the above changes has to be a migration in the intramolecular system. The rearrangement is made possible by the sterically favorable positions of the amidinium group relative to the $\mathrm{sp}^{2}$ electron lone pairs of the thymine $\mathrm{O} 2$ oxygen atom. These facts lead to the conclusion that the spatial turn can occur at elevated temperatures.

Only one averaged signal $\left(\delta_{\mathrm{N} H} 9.29 \mathrm{ppm}\right)$ for the amidinium protons of $\alpha$-(1-thyminyl)- $m$ toluamidine hydrochloride (2) is detected. As observed in benzamidine hydrochloride $\left(\delta_{\mathrm{N} H} 9.44 \mathrm{ppm}\right)$, 2 is possibly also stabilized by resonance (Scheme 2$)$ and $\Delta \delta_{\mathrm{N} H}(0.15 \mathrm{ppm})$ between the two aromatic amidines reveals that an H-bond interaction occurs. The $\mathrm{N} 3 \mathrm{H}$ signal of $\mathbf{2}$ is broadened as a result of additional interactions of the thymine hydrogen through electrostatic effects with the cation bound. In contrast to $\mathbf{2}$, the methyl group from the amidinium function can enhance the stability of structure $\mathbf{6}$ by hyperconjugation $\left(\mathrm{CH}_{2}={ }^{+} \mathrm{NH}-+\mathrm{H}^{+}\right)$. Such a stabilization does not permit formation of the carbonium ion.

Temperature effects were also studied for 2. The experimental data are more difficult to interpret, because of changes in positions of two signals. The $\mathrm{N} 3 \mathrm{H}$ broad singlet collapses and shifts upfield. There is exchange at elevated temperatures and the lifetimes become long enough to allow magnetic 


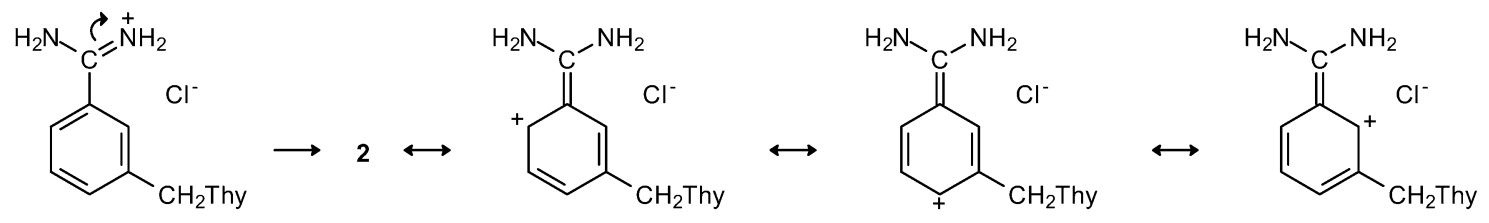

Thy= 1-thyminyl

Scheme 2. Possible stabilization of $\mathbf{2}$ by the following resonance structures, showing the effective delocalization of the positive charge.

Table 1

\begin{tabular}{lllc}
\multicolumn{4}{c}{ Dependence of $\Delta \delta_{\mathrm{N} H}$ on hydrogen bonding strength } \\
\hline Amidine & $\Delta \delta_{\mathrm{N} H}{ }^{\mathrm{a}}$ & \multicolumn{1}{c}{$\delta_{\mathrm{N} H}$} & $\delta_{\mathrm{NCH} 3}$ \\
\hline $\mathbf{1}$ & 0.02 & $9.19,9.21$ & - \\
$\mathbf{1}\left(50^{\circ} \mathrm{C}\right)$ & 0 & 9.11 & - \\
$\mathbf{1}\left(70^{\circ} \mathrm{C}\right)$ & 0.04 & $9.08,9.12$ & - \\
$\mathbf{1}\left(90^{\circ} \mathrm{C}\right)$ & 0 & 9.09 & - \\
$\mathbf{2}$ & 0 & 9.29 & - \\
$\mathbf{3 a}$ & 0.08 & $9.09,9.17$ & $2.82,3.00$ \\
$\mathbf{3 a}\left(50^{\circ} \mathrm{C}\right)$ & 0 & 9.07 & $2.83,3.00$ \\
$\mathbf{3 a}\left(70^{\circ} \mathrm{C}\right)$ & 0 & 9.05 & $2.84,3.01$ \\
$\mathbf{3 a}\left(90^{\circ} \mathrm{C}\right)$ & 0 & 9.04 & $2.86,3.03$ \\
$\mathbf{3 b}$ & 0 & 9.35 & $2.77,3.01$ \\
$\mathbf{4}$ & 0 & 8.79 & $3.15^{\mathrm{b}}$ \\
$\mathbf{8}$ & 0.50 & $8.83,9.33$ & - \\
$\mathbf{9}$ & 0.92 & $9.23,10.15$ & $2.86,2.94$ \\
$\mathbf{1 1}$ & 0.35 & $8.53,8.88$ & - \\
$\mathbf{1 2}$ & 0.34 & $8.77,9.11$ & - \\
\hline $\mathrm{a} \Delta \delta_{\mathrm{N} H}$ values of the amidine $\mathrm{NH}$ protons; \\
$\mathrm{b}$ two separate singlets are observed for 10 [22].
\end{tabular}

equivalence between the $\mathrm{N} 3 \mathrm{H}$ and ${ }^{+} \mathrm{C}\left(\mathrm{NH}_{2}\right)_{2}$ protons. It is clear that they interact with lone pairs of the $\mathrm{C} 2=\mathrm{O}$ oxygen.

The spectra of unsubstituted amidines 1-2 were compared with whose of reference compounds. It is generally assumed that for amidine salts, under restricted internal $\mathrm{H}_{2} \mathrm{NCNH}_{2}$ rotation, the $\Delta \delta_{\mathrm{N} H}$ chemical shift differences between the 'outside' and 'inside' NH protons are much higher. Table 1 presents the data for acetamidine (8) [21], 1-(3-amidinopropyl)thymine (11), and 1-(4-amidinobutyl)thymine (12) hydrochlorides.

\section{2. ${ }^{1} \mathrm{H}$ and ${ }^{13} \mathrm{C}$ NMR evidence for the intramolecular hydrogen bonds of dimethylamidines $\mathbf{3}$ and $\mathbf{4}$}

Similarly, a comparison of the $\mathrm{NH}$ signals of amidines $\mathbf{3}$ and $\mathbf{4}$, with those of appropriate $N, N^{\prime}$ dimethyl- (9) $[21,23,24]$ and $N, N$-dimethylacetamidinium (10) $[22,25]$ chlorides, gives evidence of the occurrence of intramolecularly $\mathrm{H}$-bonded stereoisomers. The experimental $\Delta \delta_{\mathrm{N} H}$ parameters used in this publication are of diagnostic value. The spectrum of 3a consists of separate signals: two $\mathrm{N} H$ singlets $\left(\Delta \delta_{\mathrm{N} H} 0.08 \mathrm{ppm}\right)$ and two $\mathrm{NCH}_{3}$ singlets; this spectral pattern can originate only from the appropriate EZ stereoisomers [26,27]. 
In the studied structure 4 , the $\mathrm{O} 2$ carbonyl oxygen connects the adjacent amidinium $\mathrm{N}$ atom by the bifurcated intramolecular $\mathrm{C}=\mathrm{O} \cdots \mathrm{H}_{2} \mathrm{~N}^{+}=\mathrm{C}-\mathrm{N}\left(\mathrm{CH}_{3}\right)_{2}$ hydrogen bond $(\mathrm{O} 2$ acts as a double $\mathrm{HB}$ acceptor). The NMR spectrum of $\mathbf{4}$ shows characteristic absorption at $8.79 \mathrm{ppm}$ (one broad singlet, $2 \mathrm{H}, \mathrm{NH}_{2}$ ). The most probable explanation of observed one sharp singlet at $3.15 \mathrm{ppm}(6 \mathrm{H})$ is the free internal rotation around the amidinium $\mathrm{C}-\mathrm{N}\left(\mathrm{CH}_{3}\right)_{2}$ bond (in contradistinction to 10).

On the contrary, the presence of three separate singlets for three NH protons is attributed to the absence of strong interactions in the monomethylamidines investigated (5: 8.91, 9.23, $9.51 \mathrm{ppm} ; \mathbf{6}: 9.04$, 9.57, $9.95 \mathrm{ppm}$ ). It appears to be little or no interaction between the two centers in N-methylamidine 6, as compared with $7(9.10,9.56,9.96 \mathrm{ppm})$. Presumably, the free rotation of the amidinium group is unfavorable for the formation of intramolecular hydrogen bonding in 5-6. The new chemical shift phenomenon observed in $\mathbf{1 - 4}$ is due to hindered rotation about the $\mathrm{N} 1-\mathrm{CH}_{2}$ bond.

According to the relative $\Delta \delta_{\mathrm{N} H}$ values, the higher stability of amidine 1 compared with 11-12 must be in part a result of higher bond strength (generally the strongest hydrogen bonds are the shortest [28]). The same result is obtained for $\mathrm{N}, \mathrm{N}^{\prime}$-dimethylamidine 3 in comparison with $\mathbf{9}$. The stabilizing contribution of intramolecular H-bonding is the highest if the $\Delta \delta_{\mathrm{N} H}$ value approaches zero. Most likely, a kind of chemical exchange $(\mathrm{N}-\mathrm{H}$ dissociation/recombination) is implied in this process.

Two points have become clear: (a) all the NH hydrogen atoms of the amidine cation are engaged in the multipoint hydrogen bonds linking them to the oxygen host, (b) it is reflected in the remarkable stability of the complexes and the enhanced chemical reactivity of thioamides towards zinc ammoniates; the complexes prevent decomposition to a nitrile [18].

\section{3. ${ }^{1} H-{ }^{15} N 2 D$ NMR studies of unsubstituted amidines $\mathbf{1}$ and $\mathbf{1 1}$}

The above spectroscopic features of $\mathbf{1}$ are attributed to intramolecular tetrafurcated hydrogen bonds. All amidinium protons involved in these bonds are represented by one singlet in the proton spectrum. This equivalence is due to the rapid exchange process.

To understand more the nature of the intramolecular interactions, the ${ }^{1} \mathrm{H}^{15}{ }^{15}$ 2D NMR spectra with natural isotopic abundance of ${ }^{15} \mathrm{~N}$ were measured (Fig. 2). The influence of the $\mathrm{O} 2$ oxygen on the ${ }^{1} \mathrm{H}-{ }^{15} \mathrm{~N}$ couplings is seen. By comparison, both complexes $\mathbf{1}$ and $\mathbf{1 1}$ do, indeed, show correlations characteristic of their amidinium ligands in the GHSQC (gradient heteronuclear single quantum coherence) spectra for reasons afore-mentioned. A loss of correlations from the $\mathrm{C} 6 \mathrm{H}$ proton to the amidinium nitrogens in 1 suggests stronger hydrogen bonds (closer $\mathrm{C}=\mathrm{O} \cdots\left(\mathrm{H}_{2} \mathrm{~N}\right)_{2} \mathrm{C}$ contacts than in 11). This spin-spin interaction through space is weakened in $\mathbf{1}$ because of a relatively longer distance. The GHMBC (gradient heteronuclear multiple bond correlation) spectra provide further insight into the cyclic structures. This investigation was facilitated by the previous confirmation of the assignment of the N1 and N3 correlations [17]. The spectra were recorded according to the literature $[17,29,30]$.

\section{Conclusion}

This study reveals that the structure of products has an important influence on the reactivity. The position of positive charge changes from typical amidinium ions (no free internal rotation) to carbonium and immonium ions. The spectroscopic investigation shows that simple amidines exist as H-bonded intramolecular complexes (characteristic features: temperature reversibility, shifting to lower frequencies at higher temperatures, non-dependence on concentration, $\Delta \delta_{\mathrm{N} H}$ values are in the proximity of zero, ${ }^{1} \mathrm{H}$ ${ }^{15} \mathrm{~N}$ characteristic couplings). One principle involved seems to be well based, the stability of products 


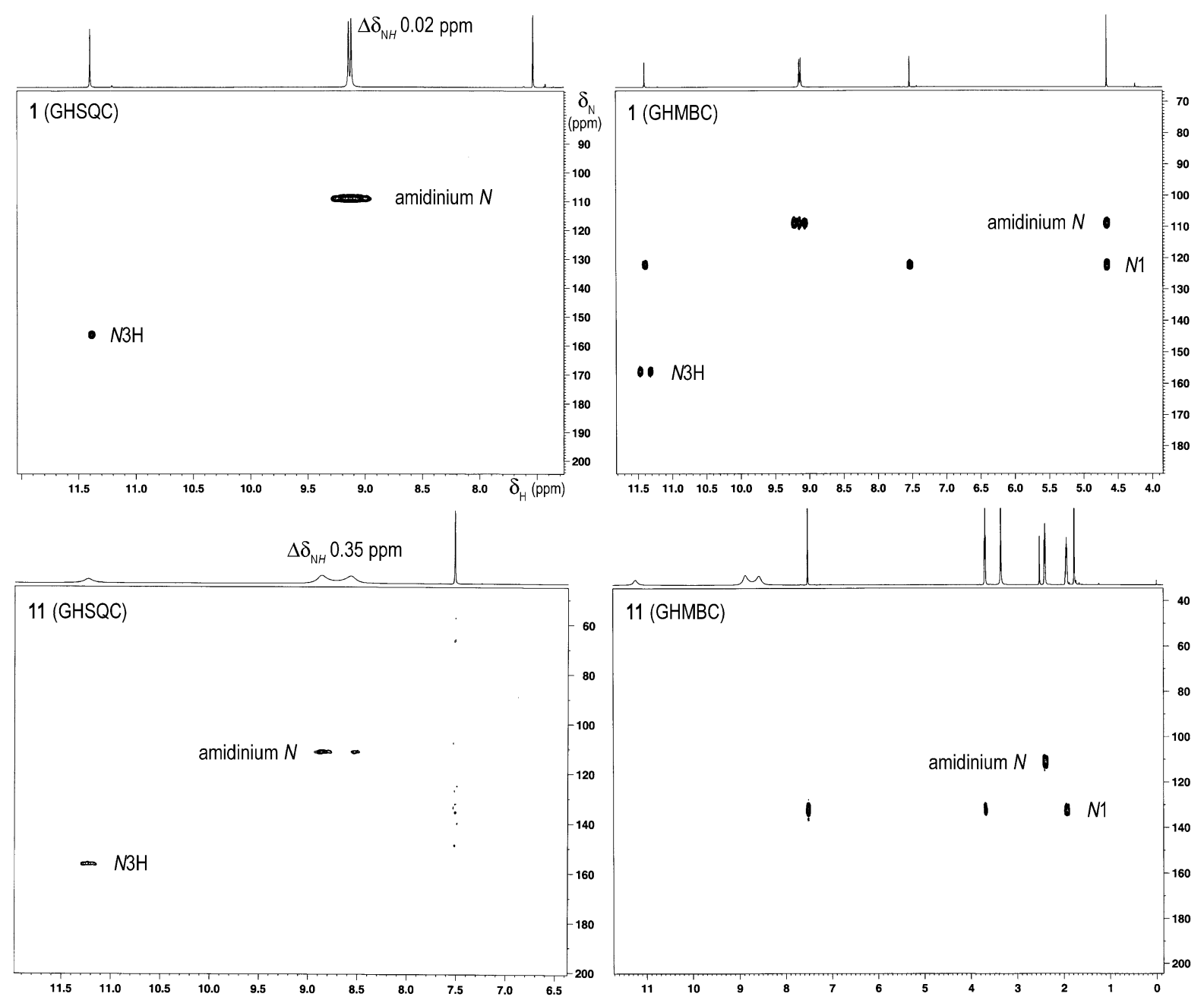

Fig. 2. The ${ }^{1} \mathrm{H}_{-}{ }^{15} \mathrm{~N}$ GHSQC (left) and GHMBC (right) spectra of $40 \mathrm{mg}$ of illustrative examples $\mathbf{1}$ and $\mathbf{1 1}$, dissolved in DMSO- $d_{6}(0.5 \mathrm{ml})$ in $5 \mathrm{~mm}$ TBI $1 \mathrm{H} / 31$ tubes. The high resolution proton spectra are plotted atop the contour plot. Data acquisition parameters are specified in the experimental section.

increases when the chemical shift difference $\left(\Delta \delta_{\mathrm{N} H}\right)$ decreases. The hydrogen bonds enhance both the stability and the reaction rate. Contrary to this analysis, which presents an extension of my earlier work [17], the $\Delta \delta_{\mathrm{N} H}$ results of some amides can be only a tool to detect interactions [31-33]. This is logical since different intermolecular hydrogen bonds could compete with weaker intramolecular interactions \{see spectroscopic [34] and crystallographic [35] data for (1-thyminyl)acetamide, $\Delta \delta_{\mathrm{N} H} 0.37 \mathrm{ppm}$ \}. On the basis of the results of the present work, the amidine groups are stronger H-bond donors than the carbamoyl $\mathrm{NH}_{2}$ group; it is reflected in their intramolecular conformational preference.

\section{References}

[1] C.T. Supuran, A. Scozzafava, F. Briganti and B.W. Clare, J. Med. Chem. 43 (2000), 1793.

[2] C.T. Supuran, F. Briganti, A. Scozzafava and M.A. Ilies, J. Enzyme Inhibit. 15 (2000), 335. 
[3] A. Scozzafava, F. Briganti and C.T. Supuran, Eur. J. Med. Chem. 34 (1999), 939.

[4] P. Dash, D.P. Kudav and J.A. Parihar, J. Heterocyclic Chem. 43 (2006), 401

[5] M. Kock, J. Junker and T. Lindel, Org. Lett. 1 (1999), 2041.

[6] S. Mallena, M.P.H. Lee, C. Bailly, S. Neidle, A. Kumar, D.W. Boykin and W.D. Wilson, J. Am. Chem. Soc. 126 (2004), 13659.

[7] J. Spychala, Monatsh. Chem. 137 (2006), 1203.

[8] J.D. Dunitz and A. Gavezzotti, Angev. Chem. Int. Ed. 44 (2005), 1766.

[9] H.J. Neusser and K. Siglow, Chem. Rev. 100 (2000), 3921.

[10] C.E.H. Dessent and K. Muller-Dethlefs, Chem. Rev. 100 (2000), 3999.

[11] P.E.S. Wormer and A. van der Avoird, Chem. Rev. 100 (2000), 4109.

[12] J.C. MacDonald and G.M. Whitesides, Chem. Rev. 94 (1994), 2383.

[13] S.J. Grabowski, Struct. Chem. 16 (2005), 175.

[14] H. Zheng, R. Zhang and J. Shen, Supramol. Sci. 5 (1998), 627.

[15] H.D. Lutz, J. Mol. Struct. 646 (2003), 227.

[16] H.D. Lutz, K. Beckenkamp and H. Moller, J. Mol. Struct. 322 (1994), 263.

[17] J. Spychala, Magn. Reson. Chem. 41 (2003), 169.

[18] J. Spychala, Catal. Lett. 109 (2006), 55.

[19] J. Spychala, J. Sulfur Chem. 27 (2006), 203.

[20] J. Spychala, Tetrahedron 56 (2000), 7981.

[21] G.S. Hammond and R.C. Neuman Jr, J. Phys. Chem. 67 (1963), 1655.

[22] C.L. Perrin and O. Nunez, J. Am. Chem. Soc. 109 (1987), 522.

[23] R.C. Neuman Jr and G.S. Hammond, J. Phys. Chem. 67 (1963), 1659.

[24] R.C. Neuman Jr, G.S. Hammond and T.J. Dougherty, J. Am. Chem. Soc. 84 (1962), 1506.

[25] R.C. Neuman Jr and V.A. Jonas, J. Phys. Chem. 75 (1971), 3532.

[26] G. Haefelinger and F.K.H. Kuske, in: The Chemistry of Amidines and Imidates, S. Patai and Z. Rappoport, eds, Vol. 2, Wiley, Interscience, Chichester, 1991, p. 1.

[27] C.L. Perrin, in: The Chemistry of Amidines and Imidates, S. Patai and Z. Rappoport, eds, Vol. 2, Wiley, Interscience, Chichester, 1991, p. 147.

[28] M.C. Buzzeo, L.N. Zakharov, A.L. Rheingold and L.H. Doerrer, J. Mol. Struct. 657 (2003), 19.

[29] D.S. Wishart, C.G. Bigam, J. Yao, F. Abildgaard, H.J. Dyson, E. Oldfield, J.L. Markley and B.D. Sykes, J. Biomol. NMR 6 (1995), 135.

[30] R. Marek, J. Brus, J. Tousek, L. Kovacs and D. Hockova, Magn. Reson. Chem. 40 (2002), 353.

[31] A. Salaun, A. Favre, B. Le Grel, M. Potel and P. Le Grel, J. Org. Chem. 71 (2006), 150.

[32] S.H. Gellman, G.P. Dado, G.-B. Liang and B.R. Adams, J. Am. Chem. Soc. 113 (1991), 1164.

[33] E.S. Stevens, N. Sugawara, G.M. Bonora and C. Toniolo, J. Am. Chem. Soc. 102 (1980), 7048.

[34] J. Spychala, Synth. Commun. 27 (1997), 3431.

[35] T. Borowiak, G. Dutkiewicz and J. Spychala, Acta Cryst. C62 (2006), o344. 


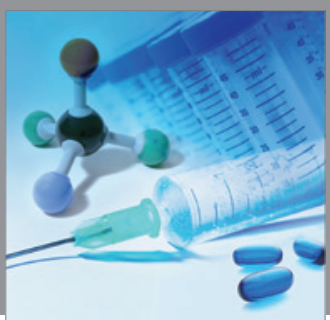

International Journal of

Medicinal Chemistry

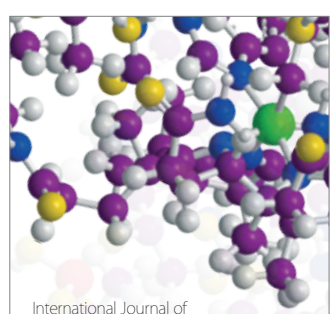

Carbohydrate Chemistry

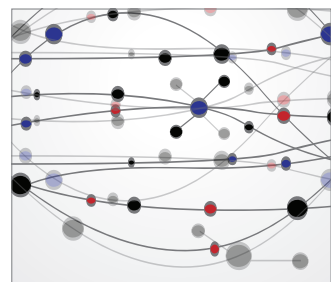

The Scientific World Journal
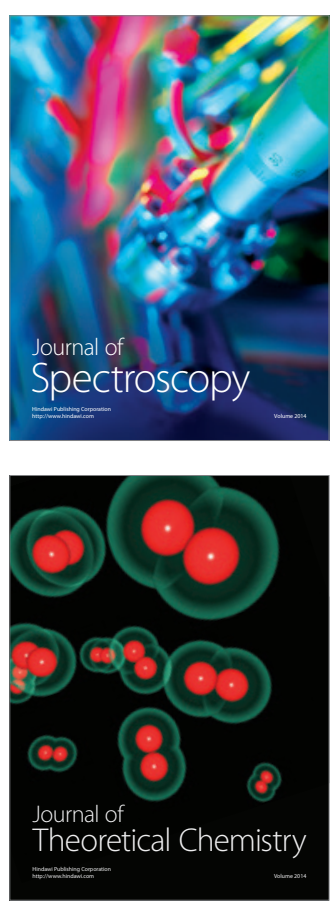
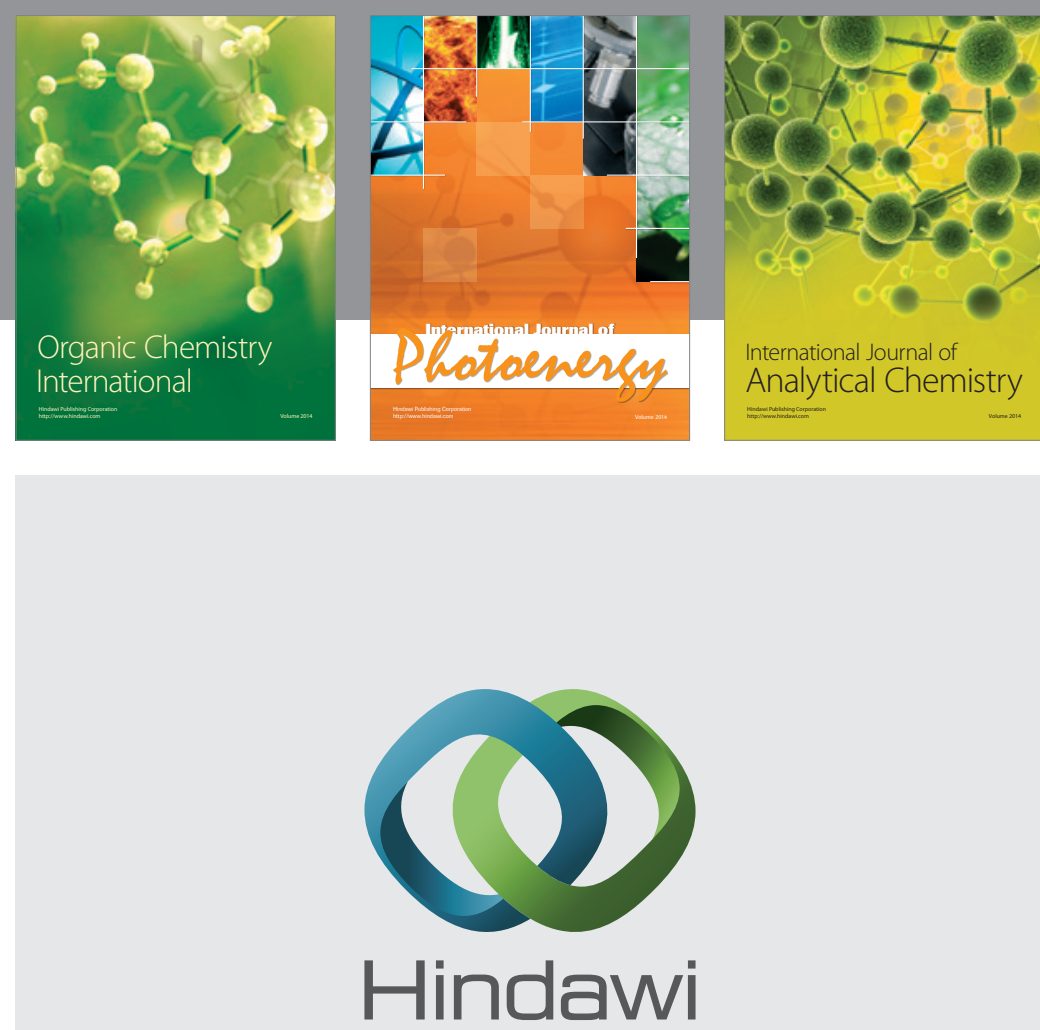

Submit your manuscripts at

http://www.hindawi.com
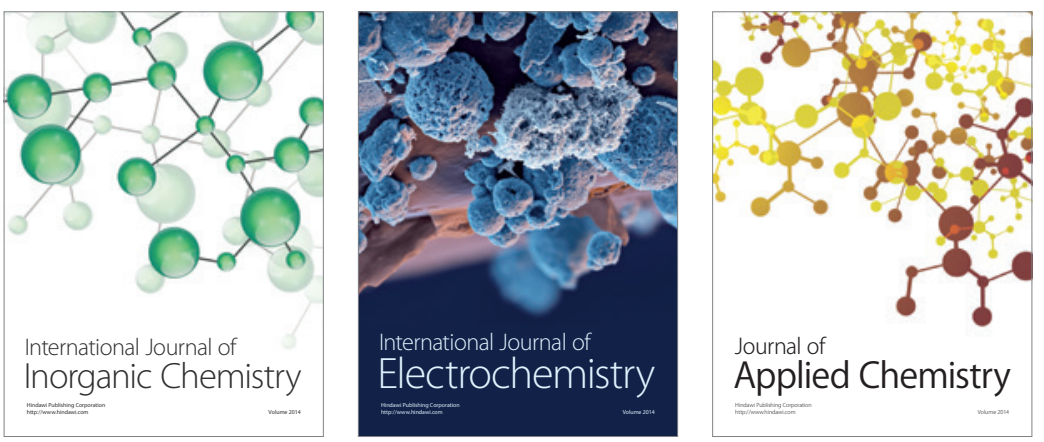

Journal of

Applied Chemistry
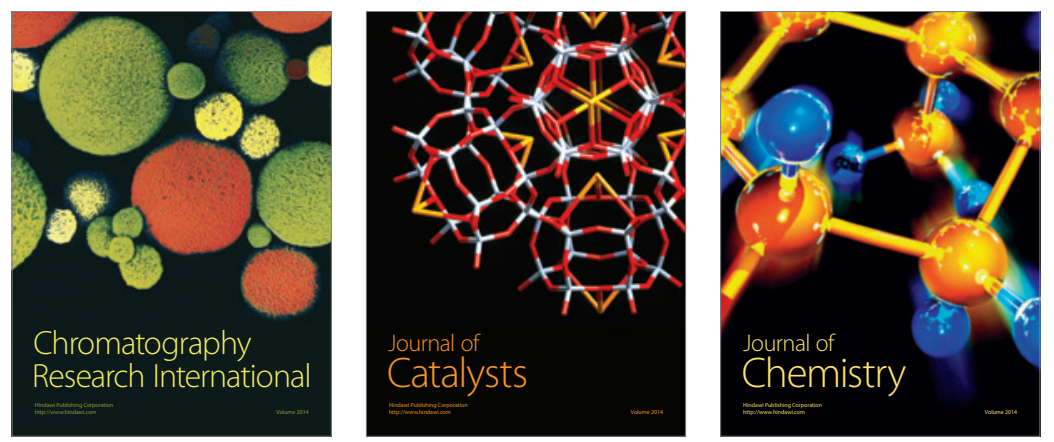
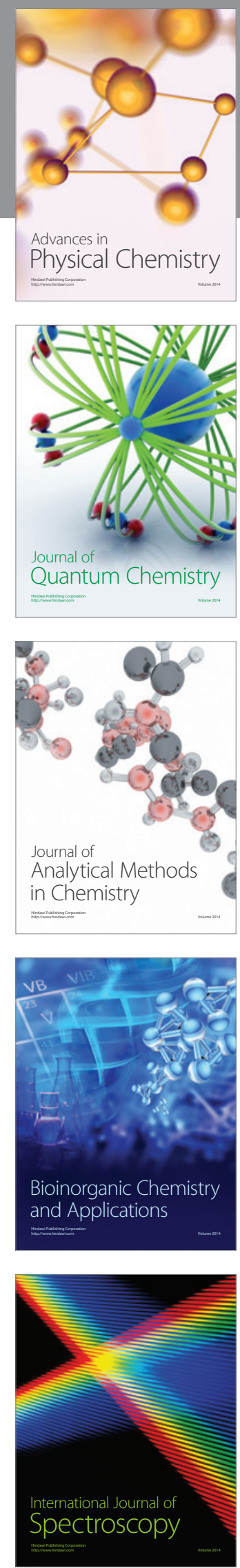